\title{
Unilateral Double Impaction of Fourth and Third Mandibular Molars: A Rare Case Report
}

\section{Apostolos N. Eliades ${ }^{a}$, Alexander Veis ${ }^{b}$}

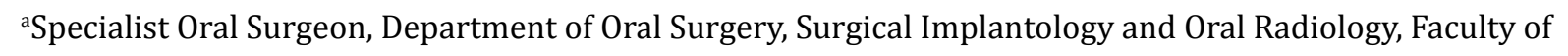
Dentistry, Aristotle University of Thessaloniki, Thessaloniki, Greece.

${ }^{\mathrm{b}}$ Assistant Professor, Department of Oral Surgery, Surgical Implantology and Oral Radiology, Faculty of Dentistry, Aristotle University of Thessaloniki, Thessaloniki, Greece. eliadesapostolos@gmail.com

*Corresponding Author: Apostolos N. Eliades, Vasileos Constantinou A' 64, 3076 Limassol, Cyprus.

\section{Abstract}

Supernumerary molars are occasionally found in a preoperative radiographic third molar evaluation. The presence of a supernumerary molar is rare and is usually impacted. Clinicians should be aware of the diagnosis and treatment of this entity. Aim of the article is to present a case of a 22 years old nonsyndromic female who was referred for a preventive extraction of third molars. The presurgical radiographic examination revealed the existence of an unilateral double impaction of a fourth and third molars in the right posterior mandible. The simultaneous surgical extraction of the fourth and third mandibular molars was performed without any postoperative complications. The preoperative radiographic evaluation was of crucial importance for the surgery.

Keywords: supernumerary molars, fourth molars, distomolars, treatment.

\section{INTRODUCTION}

Third molar extraction is one of the most common surgical procedure in oral surgery. Panoramic and periapical radiography are the standard methods for the primary preoperative examination of patients referring for third molar evaluation 1. Rarely, the presence of supernumerary teeth may be found in a routine radiographic examination of a patient 2 .

Supernumerary teeth are additional teeth occurring in the dental arch in excess of the normal number of the teeth for each quadrant 2 . The frequency with which impacted supernumerary teeth are encountered in a clinical setting is relatively high, with the majority of such cases occurring in the median maxillary region, and in a small percentage in the molar region 3,4. Supernumerary teeth in the molar region are very rare and are termed as paramolars or fourth molars (distomolars) according to their location 2, 3, 5, 6 . Paramolars are situated lingually or buccally to the molar row, whereas fourth molars situated distally to the third molars $2,7,8$. They usually have a rudimentary shape and are impacted in the jaws 2, 7, 8 .

The present article presents a rare case of unilateral double impaction of fourth and third mandibular molars.

\section{Case Presentation}

A 22 years old female was referred to our clinic for a preventive removal of third molars due to orthodontic reasons. The medical history of the patient was free and the clinical examination showed a right impacted third mandibular molar whereas the rest third molars were erupted. As a part of the preoperative radiographic evaluation, the panoramic radiograph coincidentally revealed the existence of a unilateral double impaction of a third and supernumerary fourth molar in the right mandible (Fig. 1A, 1B). The panoramic and periapical radiographs showed that the inverted impacted fourth molar was located superior and in a safe distance from the mandibular molar. The tooth had a rudimentary conical shape and it was in regular size as others molars. However, the initial radiographic evaluation was not sufficient as a 
preoperative imaging of the third molar region, because of the intimate relationship between the mandibular canal and the third molar and the close relationship of the tooth with the inferior border of the mandible. Hence, a cone beam computed tomography scan was indicated (Fig. 2). The cross-sectional images revealed a disruption of the cortical layer of the mandibular canal

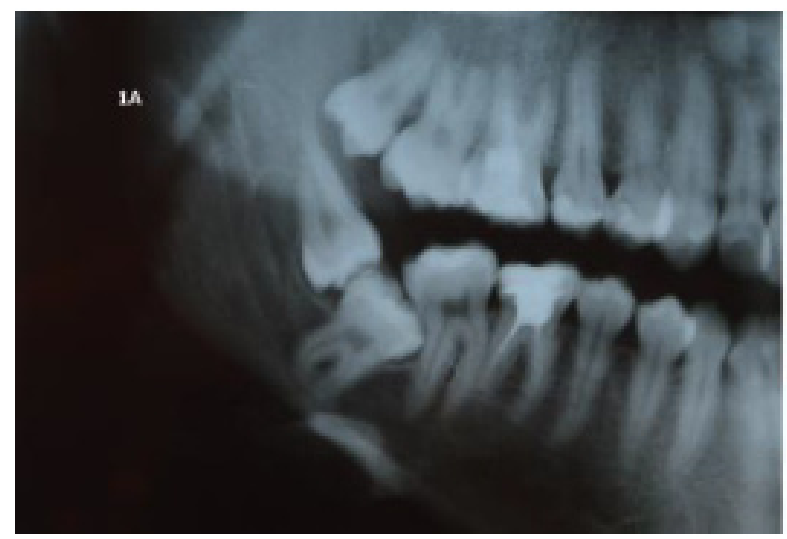

when it passed lingually and crossed the third molar. This implied the possible intra-operative exposure of the inferior alveolar neurovascular bundle and, perhaps, a risk for postoperative paresthesia of the corresponding nerve. Also, the lingual cortical plate of the mandible was found to be perforated due to the fourth and third molars crowns' proximity with it.

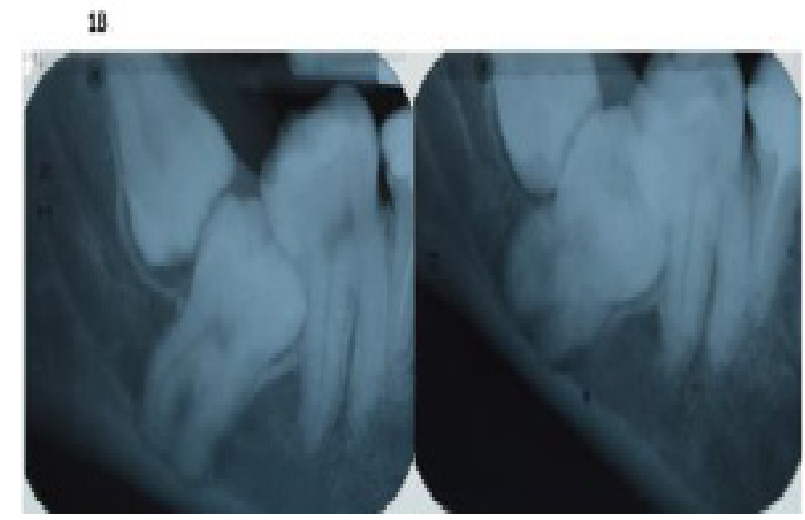

Figure 1A. Cropped panoramic radiograph of right mandibular molar region revealing the presence of a double impaction of an inverted fourth molar and a vertical third molar.

Figure 1B. The intraoral periapical radiographs with the tube shift technique of the molars'region
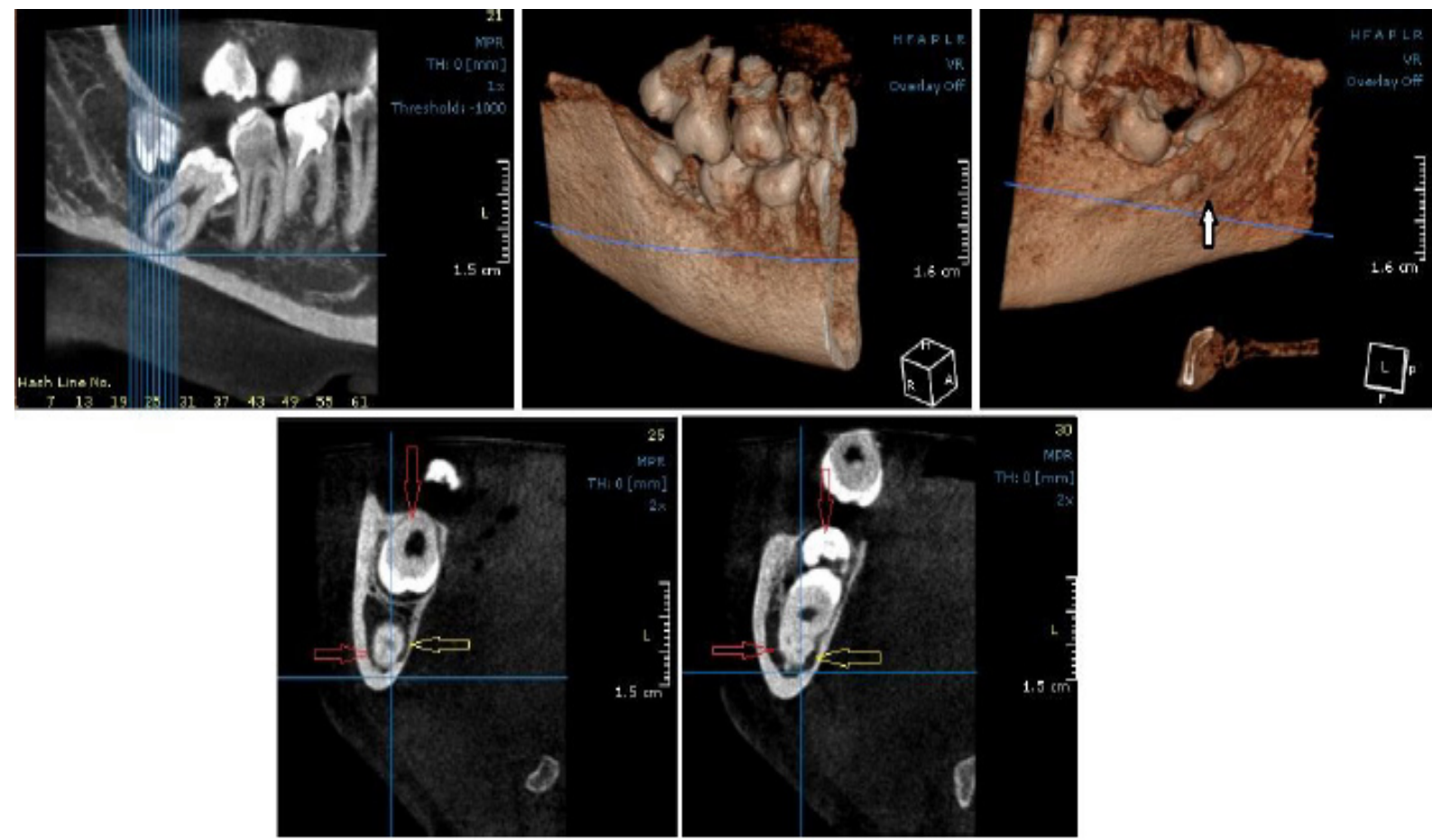

Figure 2. Cone beam computed tomography scan of the right mandibular molar region. The cross sectional slices showed the proximity of the third molar root (right arrow) with the uncorticated (cortical break) lingually positioned mandibular canal (left arrow). The fourth molar (down arrow) is situated superiorly to the crown of the third molar. The three dimensional reconstructions revealed the close relationship between the crowns of the fourth and third molars to the lingual cortical plate of the mandible resulting in cortical perforations respectively (up arrow). 
The patient was informed about the highrisk radiographic findings and any complications that may postoperatively result. Preoperatively, the patient was prescribed an antibiotic treatment with amoxicillin 500mg (1 tab every 8 hours) starting the day before and continuing for at least 5 postoperative days. Also, for anti-inflammatory and analgesic therapy was administered with ibuprofen $600 \mathrm{mg}(1$ tab every 8 hours) starting one hour before surgery and continuing for at least 3 postoperative days.

Surgery was carried out under inferior alveolar nerve block anaesthesia with anesthetic solution of mepivacaine 3\% 1:100,000 (one ampoule: $1.8 \mathrm{ml}$ ) and long buccal nerve anaesthesia with anesthetic solution of lidocaine $2 \%$ and 1:80,000 epinephrine (one ampoule: $1.8 \mathrm{ml}$ ). A sulcular incision was made starting from the mesiobuccal edge of the second molar to its distal surface and two vertical relieving incisions were made, one in the second molar region in the mesial edge without cutting the interdental papilla and the other in the mandibular ramus distally to the second molar. Thus, a mucoperiosteal flap was elevated with good visibility in the retromolar region (Fig. 3). An osteotomy was performed using a round bur with a low-speed handpiece and sterile saline irrigation. The supernumerary molar was revealed and removed (Fig. 4A, 4B). The inferior alveolar bundle was intraoperatively exposed during the extraction of the third molar (Fig. 5A, 5B, 5C), but great attention was made avoiding any injury to the bundle. After curettage of the extraction sockets the flap was repositioned with 3,0 silk sutures, leaving a small gauze for drainage, which was removed the next day. The patient was given postsurgical instructions and was reminded about medications. A mouthwash with chlorhexidine $0.2 \%$ for 7 days was also prescribed.

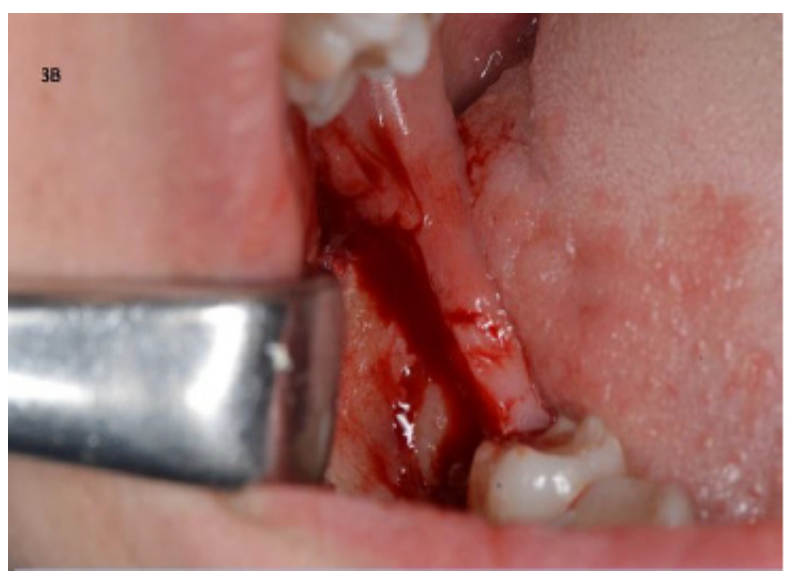

Figure 3A. Intraoral picture of the right mandibular posterior region.

Figure 3B. The surgical field after the elevation of the mucoperiosteal flap.
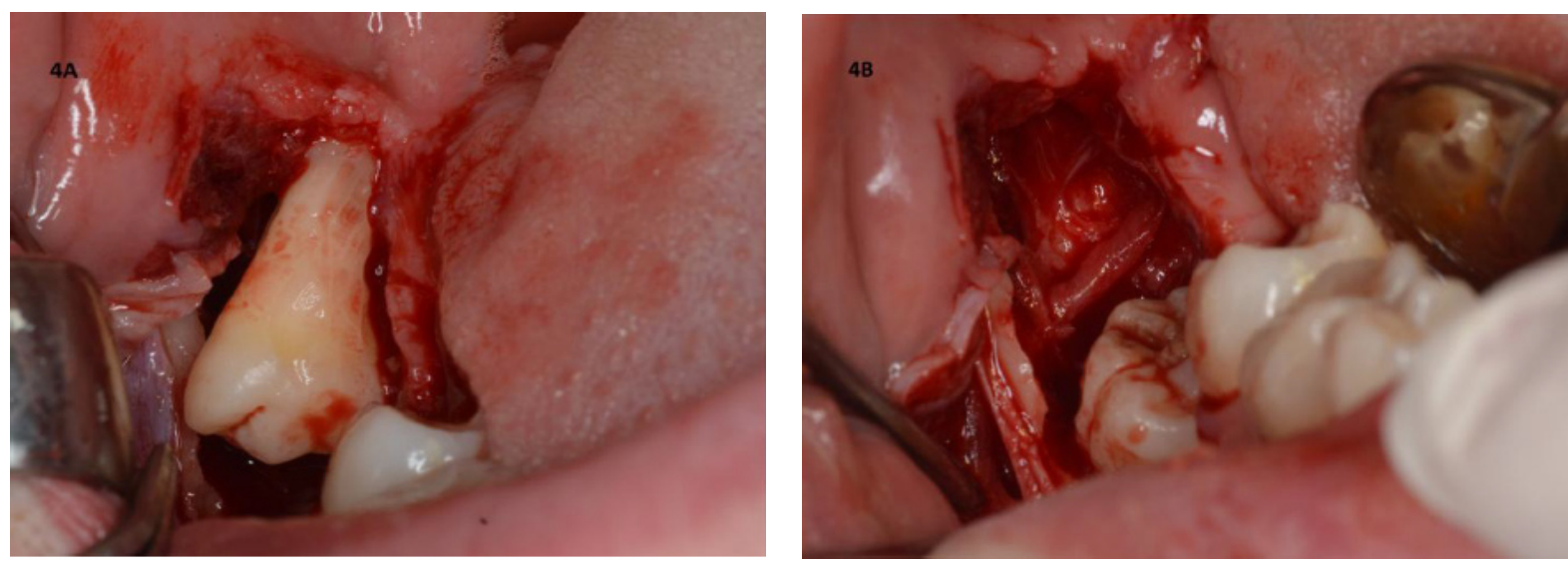

Figure 4A. Surgical extraction of the fourth mandibular molar.

Figure 4B. Postextraction socket of the fourth mandibular molar. The third mandibular molar is disclosed. 

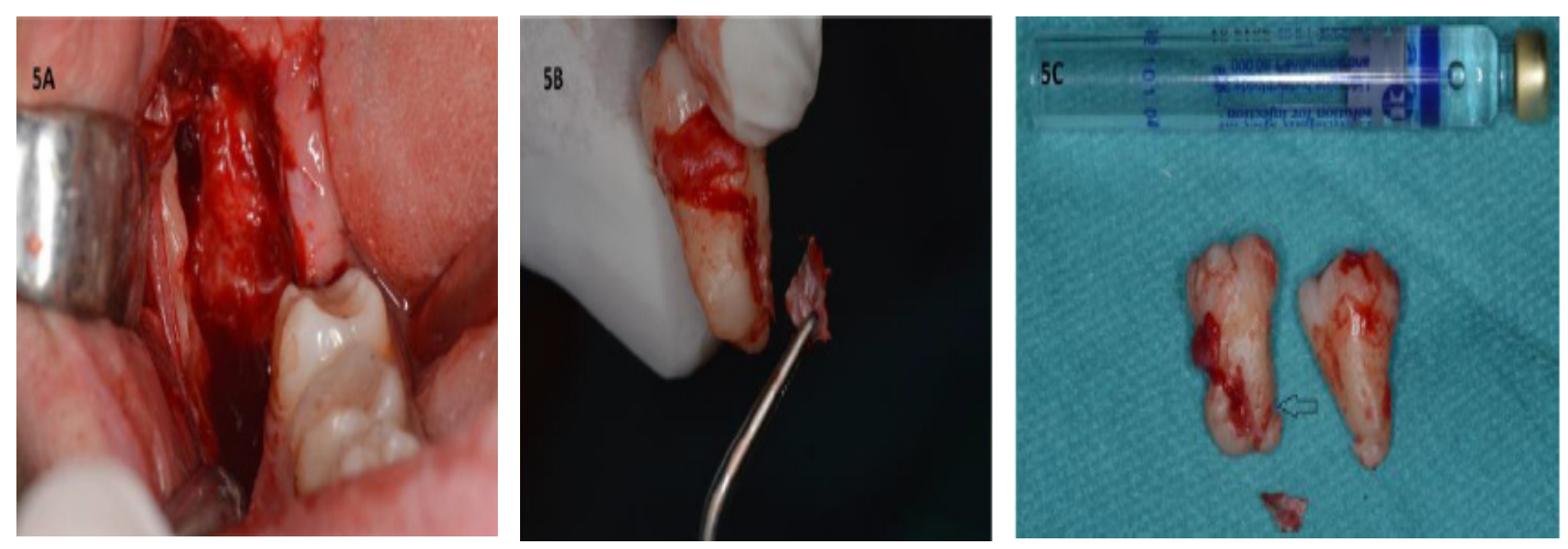

Figure 5A. Postextraction sockets of the fourth and third mandibular molars.

Figure 5B. The extracted third molar with a part of the mandibular canal's cortex.

Figure 5C. The extracted third and fourth molars. The arrow shows the root marking (hook) at the point where the lingually positioned mandibular canal crosses the mandibular third molar.

The sutures were removed after 7 days and the clinical follow-ups were done at 1 and 6 months showing a postoperative healing without any complications.

\section{Discussion/ConCLUSION}

The incidence of fourth molars has been found to be between 0.76 and $2.2 \% 5,6,9,10$. In a clinical epidemiological analysis of 173 supernumerary molars, Martinez-González et al 6recorded 137 distomolars and 36 paramolars. The etiology of supernumerary molars has not been yet clarified and various theories have beensuggested such ashereditary disorders and abnormal embryological formation2,8. Although, the existence of supernumerary molars is usually associated with nonsyndromic patients, as in our case, other studies reported an association with syndromes such as cleidocranial dysplasia, Gardners syndrome, or cleft lip and palate8.

Generally, supernumerary teeth are more common in males than in females and different ratios have been reported, whereas in fourth molar occurrence the male:female ratio was found to be close to 1:15. Similarly, in a survey on supernumerary molars, no great difference was found between the sexes in the frequency of fourth molars11. It is reported that fourth molars are more frequently found in the upper jaw (78-100\%) than in the lower one $(0-23.9 \%) 5,9,11,12$. Most patients had them unilaterally (55-76.1\%)5,11. Shahzad and Roth5 found that fourth molars were notably more common in black patients than in whites. The shape of fourth molars is reported to differ according to their location i.e. maxillary fourth molars appeared conical and pegshaped while mandibular ones as miniature third molars5,12. However, others reported supernumerary fourth and fifth molars with normal tooth morphology with regard to their crowns and roots, but slightly smaller than the existing third molars10,12. In our case report, the fourth mandibular molar had a regular shape and morphology.

In bibliography, cases where the third and fourth molars had fused into one entity are reported1316. Fusion is a tooth anomaly considered to be the result of the joining between two adjacent tooth buds during development and it also exists in less than 1\% of the population14- 16. Although fusion of teeth is most commonly reported in the deciduous dentition, particularly in the anterior teeth, fusion of fourth and third molars are reported in the permanent dentition resulting into a unique form of a supernumerary tooth fused to the distal surface of a third molar, resulting to a difficult differential diagnosis of developmental anomalies13,15,16. The radiographic evaluation may demonstrate the communication of the pulpal tissues in some fusion cases15. Furthermore, concrescence of a mandibular third molar and a supernumerary 
fourth molar is reported, which is defined as a twinning anomaly involving the union of two teeth by cementum only17.

The indications for surgical extraction of fourth molars are generally the same as to those for full impacted third molars5,12. However, the risk-benefit analysis is preoperatively estimated and in a case of surgery a minimally invasive procedure is chosen5. The surgical removal of a fourth maxillary molar encloses the risk of displacement of the tooth into the infratemporal fossa or the maxillary sinus intra-operatively5. In addition, a mandibular fourth molar may be considered as highrisk if there is a close relationship with mandibular canal and hence possibly results in inferior alveolar nerve paresthesia. In our case report, the mandibular third molar was considered as high-risk for nerve exposure and paresthesia after appropriate radiographic evaluation. Hence, careful intervention was done in order to avoid any compression to the bundle during the elevation of the tooth.

Also, the proximity of a mandibular fourth molar to the lingual cortical plate of the mandible may be result to an idiopathic or intraoperative thinning and perforation of the lingual cortical plate and hence causing an increased incidence of fracturing of the lingual cortex and/or lingual nerve injury during the surgery18-20. Thus, the risk of dislodgement of bone or tooth fragments to the soft tissues of the floor of mouth (into the submandibular and sublingual space) is increased with subsequent postoperative complications $1,20,21$. In the present case, the computed tomography scan revealed that the crowns of the third and fourth mandibular molars penetrated the lingual cortical plate and attention was taken during surgery. In addition, the surgical extraction of supernumerary molars poses the risk of fracture of the mandible2.

In the present case report, the patient was referred for a preventive removal of the third molars due to orthodontic reasons. Although, supernumerary molars are usually diagnosed as a coincidental radiological finding without any associated pathology, however, a higher percentage of associated pathological conditions was found6. One possible risk of leaving the fourth molars in place would be the development of pathological lesions (cysts, tumors) that may stem from the dental follicle or subacute pericoronitis and gingival inflammation, periodontal abscesses, root's absorption and tooth crowding2,5,8. In a clinical epidemiological analysis of 173 supernumerary molars, Martinez-González et al6 reported that mechanical-obstructive pathology was associated with $28.9 \%$, whereas enlargement of the follicular sack bigger than $3 \mathrm{~mm}$ was present in $6.2 \%$ of the sample. Nishikawa et al22 reported a patient with a large dentigerous cyst involving the crowns of the third and fourth molars. Sanghera and Jones23 reported a rare case of a parotid fistula due to an extraorally draining infected dentigerous cyst associated with a mandibular fourth molar in ascending ramus.

The decision as to whether supernumerary molars require removal or maintenance in the arch (and frequent observation) is based on their position and the likelihood of their causing any pathological lesions or problems to the dental arch2. Moreover, during the surgical extraction of the third molar, the clinician has to decide whether to simultaneous extract the fourth and third molar or extract the molars independently or keep the fourth molar in place5. It is generally thought that removing the third molar only in order to let the fourth molar move into a more favorable position (and then extract it in a second surgery) is a possible solution limiting any risks of the simultaneous surgical removal of the two molars2,5. In the present case, the surgical extraction of the fourth and third molars was performed at the same appointment. The fourth molar was located in a superior and distant position from the mandibular canal. Finally, the third molar was simultaneously removed, because it was considered that the molar would not move into a favorable position, due to his anatomical marking (hook) where it crosses the mandibular canal.

In conclusion, the decision of maintenance or surgical removal of supernumerary molars has to be evaluated individually with an appropriate preoperative radiographic examination1,5. Initial evaluation of supernumerary teeth is conducted with panoramic and 
Unilateral Double Impaction of Fourth and Third Mandibular Molars: A Rare Case Report

periapical techniques. Moreover, further radiographic examination is necessary where a fourth molar are in fusion with the third molar or high risk fourth molar is presented. Computed tomography scan may help the clinician to weigh the risks and benefits of remove these molars or not 1,5 .

\section{REFERENCES}

[1] Flygare L, Öhman A. Preoperative imaging procedures for lower wisdom teeth removal. Clin Oral Invest2000;812:291-302.

[2] Clementini M, Ottria L, Pandolfi C, Agrestini C, Barlattani A. Four impacted fourth molars in a young patient: a case report. Oral Implantology 2012;5:100-3.

[3] Ohata H, Hayashi K, Iwamoto M, Muramatsu K, Watanabe A, Narita M, Suga K, Takano N, Shibahara T. Three cases of distomolars. Bull Tokyo Dent Coll 2013;54:259-64.

[4] Rajab LD, Hamdan MA. Supernumerary teeth: review of the literature and survey of 152 cases. Int J Paediatr Dent 2002;12:244-54.

[5] Shahzad KM, Roth LE. Prevalence and management of fourth molars: a retrospective study and literature review. J Oral Maxillofac Surg 2012;70:272-5.

[6] Martínez-González JM, Cortés-Bretón Brinkmann J, Calvo-Guirado JL, Arias Irimia 0, Barona-Dorado

[7] C.Clinical epidemiological analysis of 173 supernumerary molars. Acta Odontol Scand 2012;70:398- 404. Harel-Raviv M, Eckler M, Raviv E, Gornitsky M. Fourth molars: a clinical study. Dent Update 1996;23:379-82.

[8] Reddy GS, Reddy GV, Krishna IV, Regonda SK. Nonsyndromic bilateral multiple impacted supernumerary mandibular third molars: a rare and unusual case report. Case Rep Dent 2013;2013:857147.

[9] Rao PV. Supernumerary molarteeth: observations in the skulls. Cent Afr J Med 1999;45:324-7.
[10] KoktenG,BalciogluH,Buyukertan M.Supernumerary fourth and fifth molars: a report of two cases. J Contemp Dent Pract 2003;15:67-76.

[11] Grimaris GA, Kyriakides AT, Spyropoulos ND. A survey on supernumerary molars. Quintessence Int1991;22:989-95.

[12] Piatelli A, Tetè S. Bilateral maxillary and mandibular fourth molars. Report of a case. Acta Stomatol Belg1992; 89: 57-60

[13] Hou GL, Tsai CC. Fusion of maxillary third and supernumerary fourth molars. Case report. Aust Dent J1989;34:219-22

[14] Chen HS, Huang YL. Fusion of third and fourth mandibular molars? Oral Surg Oral Med Oral Pathol 1992;73:767.

[15] Conte M, Lombardi P, Linfant J. A supernumerary tooth fused to the distal surface of a mandibular third molar. J N J Dent Assoc 2002;73:8-9.

[16] Morris DO. Fusion of mandibular third and supernumerary fourth molars. Dent Update 1992;19:177-8.

[17] Gunduz K, Sumer M, Sumer AP, Gunhan O. Concrescence of a mandibular third molar and a supernumerary fourth molar: report of a rare case. Br Dent J 2006;200:141-2.

[18] Öhman A, Kivijärvi K, Blombäck U, Flygare L. Preoperative radiographic evaluation of lower third molars with computed tomography. Dentomaxillofac Radiol 2006;35:30-5.

[19] Harada N, Vasudeva SB, Joshi R, Seki K, Araki K, Matsuda Y, Okano T. Correlation between panoramic radiographic signs and highrisk anatomical factors for impacted mandibular third molars. Oral Surg 2013;6:129-36.

[20] Jerjes W, Upile T, Shah P, Nhembe F, Gudka D, Kafas P, McCarthy E, Abbas S, Patel S, Hamdoon Z, Abiola J, Vourvachis M, Kalkani M, Al-Khawalde M,Leeson R, Banu B, Rob J, El-Maaytah M, Hopper C. Risk factors associated with injury to the inferior alveolar and lingual nerves following 
Unilateral Double Impaction of Fourth and Third Mandibular Molars: A Rare Case Report

third molar surgery-revisited. Oral Surg Oral Med Oral Pathol Oral Radiol Endod 2010;109:335-45.

[21] Tantanapornkul W, Okochi K, Bhakdinaronk A, Ohbayashi N, Kurabayashi T. Correlation of darkening of impacted mandibular third molar root on digital panoramic images with cone beam computed tomography findings. Dentomaxillofac Radiol 2009;38:11-6.
[22] Nishikawa S, Cheng J, Koyano Y, Irie T, Nomura T, Kato T, Saku T. Dentigerous cyst involving two impacted molars: Report of a Case. Oral Med Pathol 1996;1:60-2.

[23] Sanghera RK, Jones J. Parotid fistula--an extraorally draining infected dentigerous cyst associated with a supernumerary fourth molar in ascending ramus. Dent Update 2013;40:343-5.

Citation: Apostolos N. Eliades, Alexander Veis. Unilateral Double Impaction of Fourth and Third Mandibular Molars: A Rare Case Report. Archives of Dentistry and Oral Health. 2018; 1(1): 49-55.

Copyright: (C) 2018 Apostolos N. Eliades, Alexander Veis. This is an open access article distributed under the Creative Commons Attribution License, which permits unrestricted use, distribution, and reproduction in any medium, provided the original work is properly cited. 